\title{
Verslag MvO-symposium 27 september 2018
}

\author{
Mr. E.A. van Dooren*
}

Verslag van het $M v O$-symposium van 27 september 2018 met lezingen over de blockchain-AVA en de variabele beloningen voor bestuurders.

\section{Inleiding}

Op 27 september 2018 vond in Amsterdam voor de tweede keer het MvO-symposium plaats. Sinds de oprichting van het Maandblad voor Ondernemingsrecht is het een goed gebruik om ieder jaar de auteurs en redacteurs te bedanken voor hun bijdrage aan het tijdschrift. De afgelopen twee jaar is deze dankbetuiging gegoten in de vorm van een symposium en aansluitende borrel. Twee van de doelstellingen van $\mathrm{MvO}$ zijn om auteurs de ruimte te bieden voor vernieuwende ideeën en om een platform te zijn voor beginnende auteurs. Deze doelstellingen zijn op 27 september nog eens extra benadrukt. Het symposium kende als thema 'de randen van het ondernemingsrecht'. Twee sprekers hebben een lezing gegeven over onderwerpen die niet direct behoren tot het ondernemingsrecht, maar hier wel raakvlakken mee hebben. Anne Lafarre ${ }^{1}$ sprak over blockchain en hoe dit toegepast kan worden bij aandeelhoudersvergaderingen. Manuel Lokin ${ }^{2}$ vervolgde met een presentatie over variabele beloningen voor bestuurders bezien vanuit de gedragswetenschap. Daarnaast kende het symposium de introductie van de $M v O$ Talent van het jaarprijs. Deze prijs is in het leven geroepen om beginnende auteurs extra onder de aandacht te brengen en hen aan te moedigen om te publiceren.

\section{De blockchain-AVA}

Lafarre heeft empirisch onderzoek gedaan naar het gedrag van aandeelhouders bij aandeelhoudersvergaderingen. Op basis van de uitkomsten van dit onderzoek heeft zij enkele problemen geïdentificeerd waarvoor blockchain mogelijk een oplossing biedt. ${ }^{3}$

Iedere vennootschap heeft een gedelegeerd management (het bestuur) en investor ownership (de aandeelhouders). Een deel van de rechten van de aandeelhouders is gedelegeerd aan het

\footnotetext{
Mr. E.A. van Dooren is promovendus en docent bij het Molengraaff Instituut voor Privaatrecht (Universiteit Utrecht).

1. Anne Lafarre is universitair docent bij Tilburg University.

2. Manuel Lokin is hoogleraar bij het Molengraaff Instituut voor Privaatrecht (Universiteit Utrecht) en advocaat te Amsterdam.

3. Zie ook A.J.F. Lafarre \& C.F. van der Elst, De algemene vergadering van aandeelhouders: van een niet-representatieve formaliteit naar een modern beslissingsplatform, $\mathrm{MvO} 2018$, afl. 10-11, p. 294-300.
}

bestuur, maar belangrijke controle- en beslissingsrechten zijn niet gedelegeerd. De aandeelhoudersvergadering heeft daarom twee functies: besluitvorming en controle van het bestuur. Lafarre merkt op dat veel van de procedurele voorschriften omtrent het functioneren van de aandeelhoudersvergadering niet zijn veranderd sinds de negentiende eeuw. In de praktijk wordt de naleving van deze voorschriften doorgaans gezien als dull mandatory rituals.

Lafarre wijst op drie problemen met betrekking tot de aandeelhoudersvergadering waarvoor blockchain mogelijk een oplossing kan bieden. Ten eerste het aandeelhoudersabsenteïsme. In 2014 ging slechts 50\% van de 'kleine' aandeelhouders naar de aandeelhoudersvergadering. Hiervoor zijn verschillende redenen te noemen. Dergelijke aandeelhouders hebben bijvoorbeeld een relatief beperkte invloed bij een stemming en als zij het niet eens zijn met het beleid van de vennootschap is het voor hen eenvoudiger om de aandelen te verkopen dan te proberen het beleid te wijzigen.

Een ander probleem is dat het overgrote deel van de aandeelhouders niet meer fysiek aanwezig is bij de aandeelhoudersvergadering, maar gebruikmaakt van de mogelijkheid om op afstand te stemmen. Dit leidt ertoe dat de besluitvorming op de vergadering niet meer een vrucht van onderling overleg is. Als gedurende de aandeelhoudersvergadering een agendapunt wordt gewijzigd, is het mogelijk dat stemmen worden uitgebracht ten aanzien van een onderwerp dat de aandeelhouder in eerste instantie niet voor ogen had.

Als laatste wijst Lafarre op het risico van miscommunicatie in de keten van tussenpersonen. Dit kan tot gevolg hebben dat informatie van de vennootschap niet of onjuist bij de aandeelhouders komt. Daarnaast kan het ertoe leiden dat een stem van een aandeelhouder niet of onjuist wordt uitgebracht op de aandeelhoudersvergadering.

Blockchain biedt volgens Lafarre een oplossing voor bovenstaande problemen. In tegenstelling tot een 'regulier' register wordt bij blockchain de data niet door één centrale instantie beheerd, maar door alle gebruikers gezamenlijk. Als een gebruiker een wijziging wil doorvoeren, heeft hij goedkeuring nodig van - een bepaalde percentage van - de andere gebruikers. Deze andere gebruikers controleren dat de voorgestelde wijziging correct is en is toegestaan. Hierdoor is de kans op 


\section{Maandblad}

Ondernemingsrecht

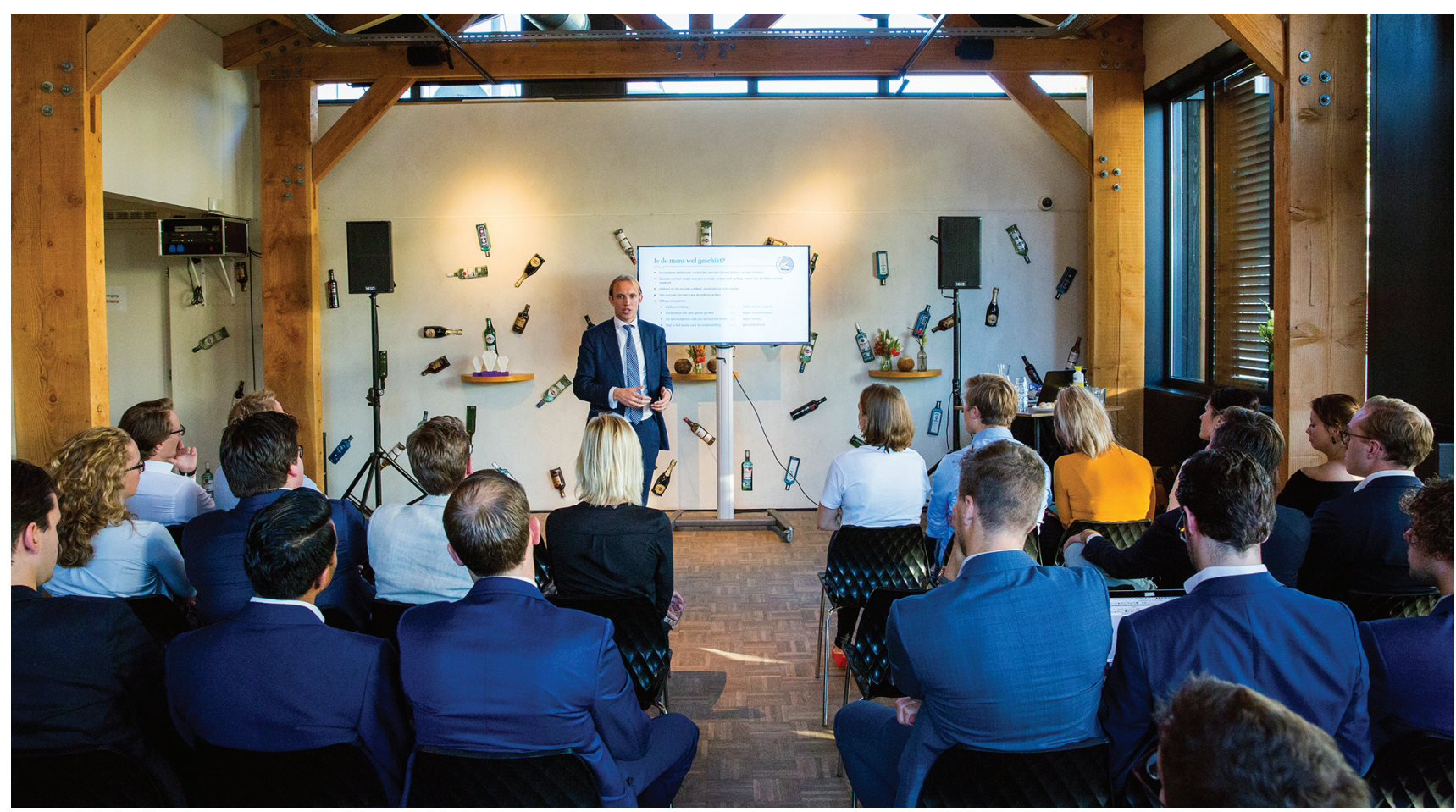

fouten - en fraude - aanzienlijk minder groot dan bij een register dat centraal wordt beheerd.

Lafarre noemt verschillende mogelijkheden hoe blockchain een aandeelhoudersvergadering kan ondersteunen. Ten eerste is het mogelijk om met blockchain bij te houden wie de aandeelhouders van de vennootschap zijn. Dit bevordert de transparantie omdat dan eenvoudig inzichtelijk is hoeveel stemrecht iedere aandeelhouder heeft en welke rechten daaraan zijn verbonden. Daarnaast kunnen de vennootschap en de aandeelhouders door middel van blockchain zonder tussenkomst van een tussenpersoon met elkaar communiceren. De vennootschap kan direct informatie met de aandeelhouders delen en de aandeelhouders kunnen zelf hun stem uitbrengen op de aandeelhoudersvergadering. Dit bevordert de betrouwbaarheid van de informatie en de stemmen. Daarnaast zorgt het ervoor dat er minder transactiekosten hoeven te worden betaald. Resumerend stelt Lafarre dat de voordelen van het gebruik van blockchain de kleinere aandeelhouders kunnen stimuleren om meer deel te nemen aan de aandeelhoudersvergadering.

\section{Variabele beloning voor bestuurders}

Lokin gaf een lezing over variabele beloningen voor bestuurders. ${ }^{4} \mathrm{Hij}$ merkt op dat dergelijke beloningen verschillende functies kunnen hebben. Zo kan een beloning worden gezien als compensatie voor geleverde inspanningen en tijd, heeft zij een signaalfunctie en kan zij worden ingezet om nieuwe bestuurders aan te trekken en bestaande bestuurders te behouden. Daarnaast kunnen variabele beloningen worden gebruikt om kostenflexibiliteit te bewerkstelligen - als het financieel slecht gaat met de onderneming hoeft zij minder te betalen aan beloningen. Vanaf het begin van de jaren negentig is de nadruk steeds meer komen te liggen op het gebruiken van beloningen om bestuurders te motiveren bepaalde (vooraf vastgestelde, veelal objectief meetbare) doelstellingen te behalen.

Sinds 1995 worden in Europa steeds omvangrijkere variabele beloningen uitgekeerd. $\mathrm{Na}$ de economische crisis is het gebruik van variabele beloningen echter onder een vergrootglas komen te liggen. Kort gezegd zijn er twee standpunten te onderscheiden ten aanzien van variabele beloningen. Enerzijds wordt betoogd dat het bieden van een variabele beloning aan bestuurders een effectieve manier is om bepaalde doelen te bereiken, mits de voorwaarden voor het toekennen van de beloning goed zijn doordacht en op een juiste wijze contractueel zijn vastgelegd. Er moet dus sprake zijn van een optimaal contract zonder perverse prikkels. Lokin werpt de vraag op of het wel mogelijk is om een optimaal contract op te stellen wanneer het doel van de variabele beloning het motiveren van de bestuurder is. De crux zit daarbij in het vertalen van het gewenste succes naar een geschikte prestatiemaatstaf. De beloning moet zijn gekoppeld aan een prestatie die bijdraagt aan het uiteindelijke doel van de onderneming (doelrealisatie), omdat anders een beloning wordt betaald zonder dat het doel wordt bereikt. Daarnaast zal de bestuurder maximale invloed moeten kunnen uitoefenen op het behalen van de gestelde

4. Zie ook E.C.H.J. Lokin, Bezoldiging van beursgenoteerde vennoot schappen (diss. Rotterdam), Deventer: Wolters Kluwer 2018, hoofdstuk $9 \mathrm{t} / \mathrm{m} 13$. 


\section{Maandblad}

Ondernemingsrecht

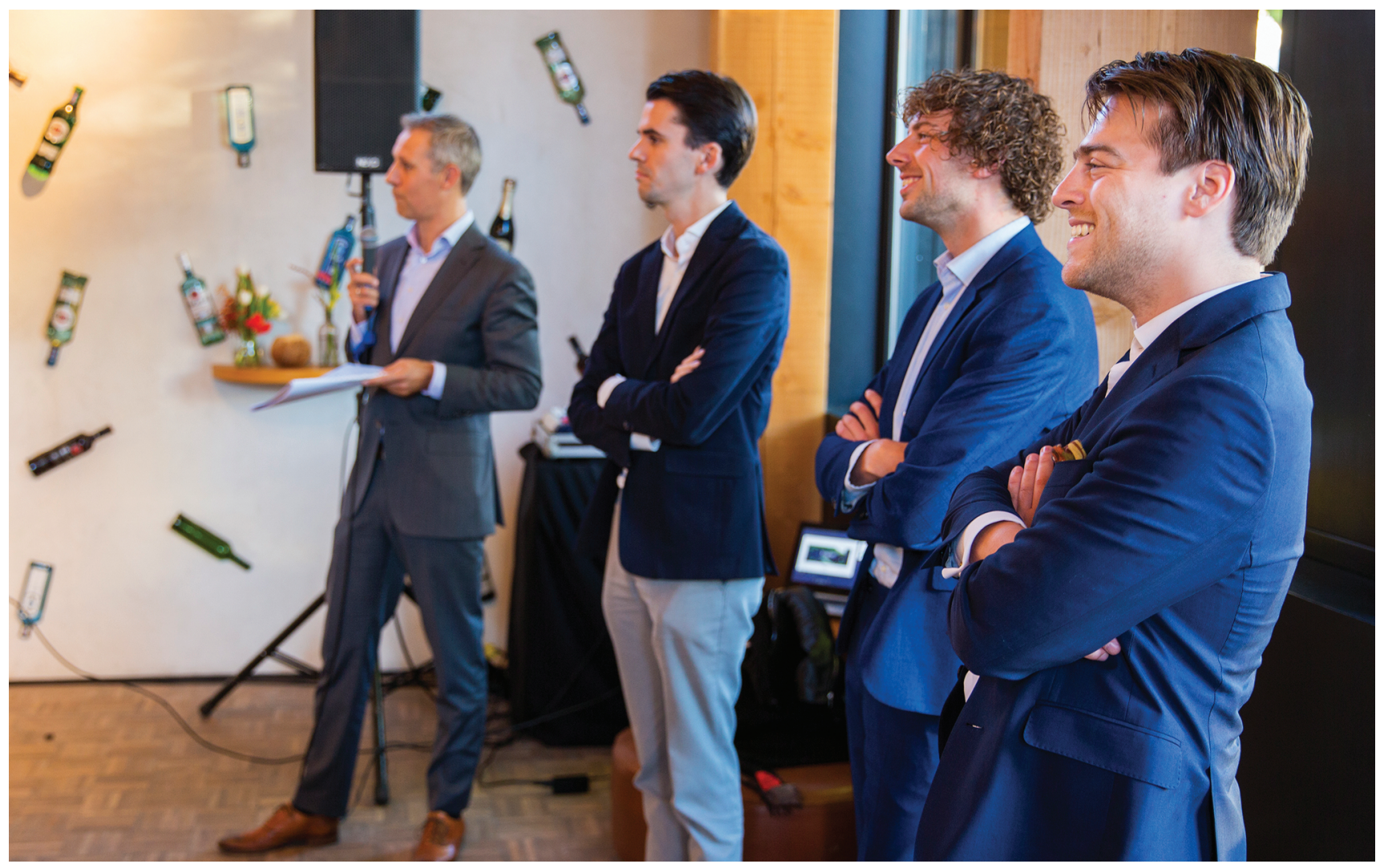

prestatiemaatstaf - en daarmee op de beloning - om daadwerkelijk gemotiveerd te worden (beïnvloedbaarheid). Een prestatiemaatstaf die maximaal scoort op zowel doelrealisatie als beïnvloedbaarheid is echter niet voorhanden, er is zelfs sprake van een afruil tussen beide. In de praktijk wordt daarom gekozen voor suboptimale prestatiemaatstaven, die hoog scoren op het een, maar lager op het ander, waardoor er altijd gewerkt zal worden met een prestatiemaatstaf die ofwel niet (echt) motiveert (er is dan eigenlijk sprake van allocatie), ofwel aan kan zetten tot een bepaald handelen dat niet direct in het belang van de onderneming hoeft te zijn. Aan de mogelijkheid om een optimaal contract vorm te geven kan dan ook ernstig worden getwijfeld.

Aan de andere kant wordt verdedigd dat het vooraf proberen te sturen van bestuurders door het vooruitzicht op een financiële beloning niet bijdraagt aan het belang van de onderneming. Het introduceren van een dergelijke extrinsieke prikkel zorgt ervoor dat de sociale context die de bestuurder moet aanzetten tot pro-organisatorisch gedrag verandert en de bestuurstaak meer wordt gepercipieerd als een markttransactie. Daarbij wordt de bestuurder telkens aangezet om bij zijn handelen nadrukkelijk zijn eigen belang te betrekken. Dit gedrag, in combinatie met suboptimale prestatiemaatstaven, zorgt ervoor dat het voor kan komen dat 'prestaties' worden behaald en variabele beloningen worden uitgekeerd zonder dat de onderneming daar daadwerkelijk bij gebaat hoeft te zijn. De directe aanwezigheid van een eigen financieel belang bij de uitvoering van de bestuurstaak brengt daarnaast een bestuurder continu in de verleiding om aan zichzelf te verklaren waarom een bepaald handelen dat leidt tot een (hogere) variabele beloning gerechtvaardigd is, zelfs wanneer hierdoor schade wordt toegebracht aan de onderneming. Hierdoor neemt de kans op veronachtzaming van het (langetermijn)belang van de onderneming toe.

Lokin sluit zich aan bij laatstgenoemd standpunt. Volgens hem leidt het vooraf sturen van bestuurders door middel van het vooruitzicht op een beloning op basis van vooraf bepaalde, objectief meetbare prestatiemaatstaven niet tot een wenselijke uitkomst. Hij meent dat de gedachte om een bestuurder te motiveren of te sturen moet worden losgelaten. Daarmee is niet gezegd dat variabele beloningen in hun geheel dienen te worden verbannen, maar wel dat kritisch moet worden gekeken naar welke functie(s) de variabele beloning heeft. Zo kan een variabele beloning onmisbaar zijn voor een onderneming vanwege een noodzaak tot kostenflexibiliteit of om onder omstandigheden bepaalde sleutelpersonen te behouden. Daarnaast kan een variabele beloning een belangrijk instrument zijn om daadwerkelijk gerealiseerd succes te verdelen binnen de onderneming (allocatie). ${ }^{5}$ In dat laatste geval speelt beïnvloedbaarheid geen rol, maar slechts doelrealisatie. Het helder formuleren van de specifieke functie(s) van de variabele beloning zal zorgen voor een meer op maat gesneden beloning en

5. Zie bijvoorbeeld de recente wijziging van de langetermijnbeloning van de raad van bestuur van SBM Offshore. 


\section{Maandblad}

daarnaast bijdragen aan de kracht van het verhaal achter het beloningsbeleid richting de stakeholders.

\section{$4 \mathrm{MvO}$ Talent van het jaar-prijs}

De afgelopen jaren hebben veel auteurs het speelveld van de juridische wetenschap betreden via $\mathrm{MvO}$. Om deze ontwikkeling verder te ondersteunen is de $\mathrm{MvO}$ Talent van het jaarprijs geïntroduceerd. Alle auteurs die in de periode van juli 2017 tot en met juni 2018 een artikel hebben gepubliceerd in $\mathrm{MvO}$ en op het moment van publicatie maximaal vier jaar (juridische) werkervaring hadden, kwamen in aanmerking voor de prijs. De jury voor de $\mathrm{MvO}$ Talent van het jaar-prijs bestond uit: prof. M.J. Kroeze (voorzitter), prof. M. Olaerts en prof. J.B.S. Hijink.

De shortlist voor de MvO Talent van het jaar-prijs omvatte:

- E. Breukink ('Een investeringstoets voor vitale vennootschappen'); ${ }^{6}$

- K.H.M. de Roo ('Het lichaam van de niet-uitvoerende bestuurder'); $;^{7}$ en

- P.L. Hezer ('Het special committee naar Amerikaans model bij openbare biedingen'). ${ }^{8}$

De jury merkte op positief verrast te zijn door het niveau van de artikelen, maar is uiteindelijk tot de conclusie gekomen dat het artikel van Hezer erboven uitsteekt. De jury heeft bijzondere waardering voor de koppeling die Hezer makt tussen theorie en praktijk en zijn vergelijking met het Amerikaanse recht. De prijs die Hezer ontvangt, bestaat uit een geldbedrag van $€ 1500$, vrij te besteden aan juridisch (ondernemingsrechtelijk) onderzoek. Daarnaast was er voor alle drie de auteurs een tastbare herinnering in de vorm van een $3 \mathrm{D}$ geprinte tombstone. Bij mijn beste weten de eerste (en enige) 3D geprinte tombstones ter wereld.

\section{Vooraankondiging $\mathrm{MvO}$-symposium voor promovendi}

Voor alle promovendi op het gebied van het ondernemingsrecht en het financieel recht organiseert $\mathrm{MvO}$ op woensdag 29 mei 2019 een symposium in Utrecht. Het thema van het symposium is tweeledig. Allereerst wordt ingegaan op de belangrijkste ontwikkelingen in deze rechtsgebieden van de afgelopen twintig jaar en hoe zij van invloed zijn op de huidige rechtspraktijk. Daarnaast gaan we ook proberen om een antwoord te geven op de vraag wat de grote ondernemingsrechtelijke en financieelrechtelijke thema's van de komende twintig jaar zullen worden. Promovendi zullen binnenkort voor het symposium worden uitgenodigd.

6. E. Breukink, Een investeringstoets voor vitale vennootschappen, $\mathrm{MvO}$ 2017, afl. 8-9, p. 177-183.

7. K.H.M. de Roo, Het lichaam van de niet-uitvoerende bestuurder, $\mathrm{MvO}$ 2017, afl. 10-11, p. 250-252.

8. P.L. Hezer, Het special committee naar Amerikaans model bij openbare biedingen, $\mathrm{MvO} 2017$, afl. 10-11, p. 266-275. 